\title{
HLA-related heterogeneity in seasonal patterns of diagnosis in Type 1 (insulin-dependent) diabetes
}

\author{
C. R. Weinberg ${ }^{1,3}$, T. L. Dornan ${ }^{1,2, *}$, J. A. Hansen ${ }^{2,4,5}$, P. K. Raghu ${ }^{1,2}$ and J. P.Palmer ${ }^{1,2}$ \\ ${ }^{1}$ Diabetes-Endocrinology Research Center, ${ }^{2}$ Department of Medicine, ${ }^{3}$ Department of Biostatistics, ${ }^{4}$ Puget Sound Blood Center, and \\ ${ }^{5}$ Fred Hutchinson Cancer Research Center, University of Washington, Seattle, Washington, USA
}

\begin{abstract}
Summary. HLA type, time of year of diagnosis, and age at diagnosis were studied in 52 new cases of Type 1 diabetes in Seattle, Washington. Diagnosis was found to be seasonal in diabetic patients positive for DR3 $(p<0.005)$, with the expected marked reduction in new cases during the summer months. This seasonality was not age-related $(p>0.13)$. Cases who were DR3-negative did not show significant seasonality of diagnosis $(p>0.5)$. However, when age at diagnosis was adjusted for, a seasonal effect was found in the DR3-negative group
\end{abstract}

$(p<0.006)$, with older cases favouring a spring onset and younger cases favouring an autumn onset. Thus, DR3-positive cases showed a seasonal diagnosis pattern that did not depend on age, while DR3-negative cases showed an age-dependent seasonal pattern. These differences may reflect the predominance of different aetiological mechanisms in these two genetic groups.

Key words: Seasonality, Type 1 diabetes, HLA, aetiology.
The onset of Type 1 (insulin-dependent) diabetes follows a seasonal pattern, with increased incidence of new cases in the autumn and late winter, followed by a nadir during the summer [1-6]. This pattern appears to be inverted in the southern hemisphere [7] and may not be present in children who develop diabetes in their pre-school years $[5,8]$.

Certain HLA antigens are now known to be associated with an increased risk of Type 1 diabetes $[9,10]$. However, the primary mechanisms of $\mathrm{B}$ cell damage may differ in patients with different HLA phenotypes $[11,12]$. In this study, we have investigated whether certain HLA specificities mark subgroups of Type 1 diabetic patients with different patterns of diagnosis, taking into account a possible relationship between season and age at diagnosis.

\section{Subjects and methods}

We studied 54 unrelated cases of newly diagnosed Type 1 diabetes, with a diagnosis between March 1976 and March 1981, who volunteered for a prospective study [13]. All patients were between 5 and 20 years of age at diagnosis; the median age at diagnosis was 10.5 years. Forty-eight patients were typed for HLA-DR and 31 were typed for HLA-D. The four patients typed for HLA-D, but not DR, were all HLA-D3-negative and were assumed to be DR3-negative

* Present address: City Hospital, Nottingham NG5 1PD, UK. also. This assumption was felt to be reasonable since among 18 D3negative patients who were also DR typed, only one was DR3-positive. Further, no set of reclassifications for those four patients and subsequent repeat analysis would materially alter our conclusions. Serological typing for DR was performed by standard methods [14, 15]. Typing for HLA-D was performed using HLA-D homozygous typing cells as previously described [16].

Statistical analysis of this data presents special problems, since time of year should be treated as a circular variable (December 31 being adjacent to January 1). For testing for seasonality, versus a null hypothesis of uniformity, the non-parametric test developed by Hodges and Ajne was applied [17]. The seasonal patterns for DR3-positive versus DR3-negative cases were compared using an approximation to the permutation distribution of a rank-based statistic [18].

Since age is a linear variable, the joint distribution of age and time of year of diagnosis can be considered as residing on a cylinder. Accordingly, the regression model of Gould [19] was applied to study the relationship between age and time of year of diagnosis. This model allows the mean of the circular variable (time of year) to depend on age in a linear way. Significance tests for the regression analyses were based on the approximately chi-squared likelihood ratio statistic, following application of Gould's model. The $p$-values given are twosided.

The regression line plotted is based on maximum likelihood estimates of the regression parameters. For the figures, the consecutive years of the study have been collapsed to 1 year.

\section{Results}

Twenty-four patients (46\%) were DR3-positive, 37 (71\%) were DR4-positive and $14(27 \%)$ were positive for both DR3 and DR4. Dates (i.e. time of year) of diagno- 


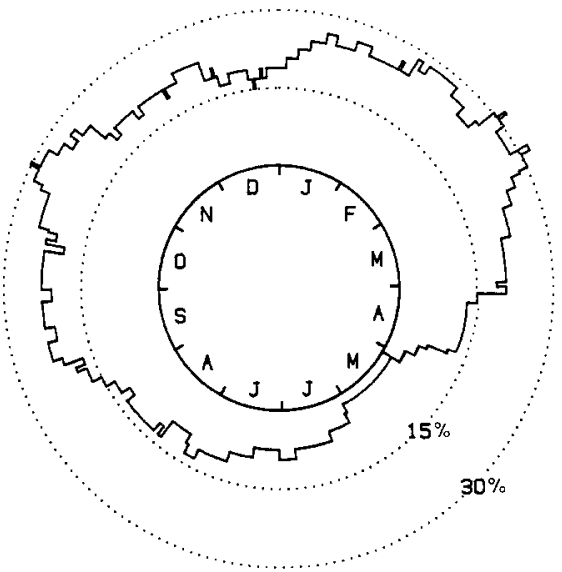

Fig. 1. The distribution of times of year of diagnosis (indicated by month) for the whole sample $(n=54)$ of newly diagnosed Type 1 diabetic patients. The radial distance outward from the circle represents the percentage of cases diagnosed within 30 days (on either side) of the corresponding date

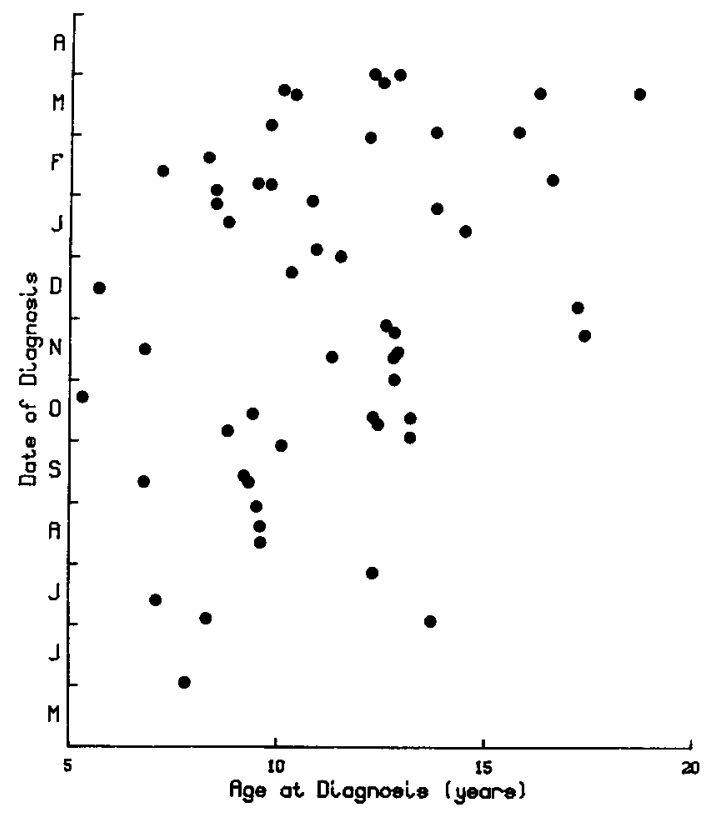

Fig.3 Date of diagnosis plotted against age for the whole sample $(n=54)$

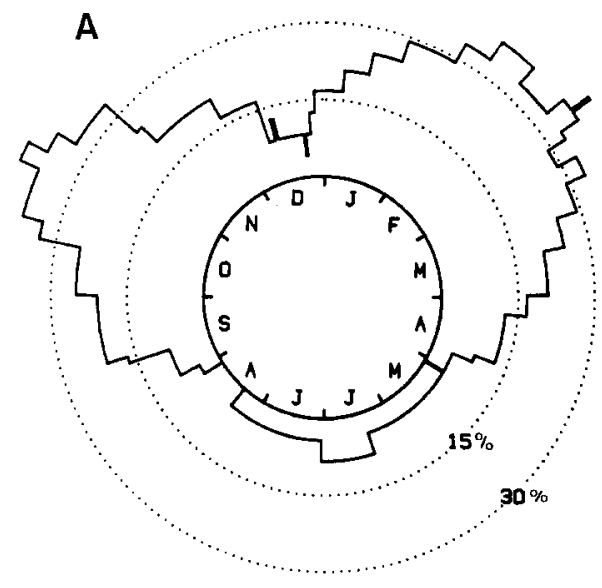

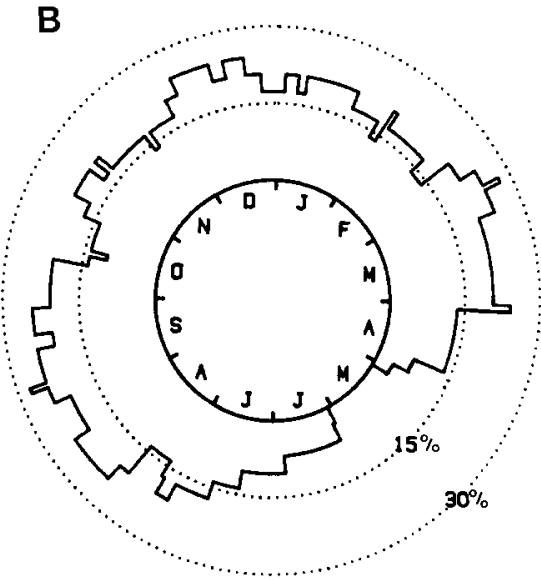

Fig. 2. A The distribution of times of year of diagnosis (indicated by month) for the 24 DR3-positive cases. B The distribution of times of year of diagnosis (indicated by month) for the 28 DR3-negative cases sis showed a statistically significant non-uniformity $(p<0.002)$, with a pattern similar to that reported by others (Fig. 1). When the data were partitioned according to the HLA-DR phenotype, we found significant non-uniformity in the dates of diagnosis for the 24 DR3-positive cases $(p<0.005)$, but not in the remaining 28 DR3-negative cases $(p>0.50$; Fig. $2 \mathrm{~A}$ and B); and the difference between the distributions for patients with DR3 versus those without was significant $(p<$ 0.04).

Males and females were similar in their times of diagnosis. In addition, we explored the relationship between age at diagnosis and date of diagnosis and observed a tendency $(0.10<p<0.13)$ for younger cases to have their diagnosis in the autumn and older cases to be diagnosed in the winter (Fig. 3). When the sample was divided according to DR3 type, the relationship was apparent $(p<0.006)$ in the DR3-negative group (Fig.4B), but not evident at all $(p>0.13)$ in the DR3-positive group (Fig. 4A).

\section{Discussion}

To our knowledge, only four previous studies have investigated whether seasonal onset of Type 1 diabetes varies with HLA type. Rolles et al. [21] studied 56 cases of Type 1 diabetes. They found significant non-uniformity in the month of diagnosis for the cases positive for HLA-B8 (then designated HL-A8), but not in the B8negative cases. Barbosa et al. [22] were unable to confirm Rolles' finding [21]. However, Rolles' sample was derived from a children's hospital, while Barbosa studied juvenile-onset diabetes patients with microangiopathy and onset before 35 years of age, suggesting that the two populations may differ. Cudworth et al. [20] 

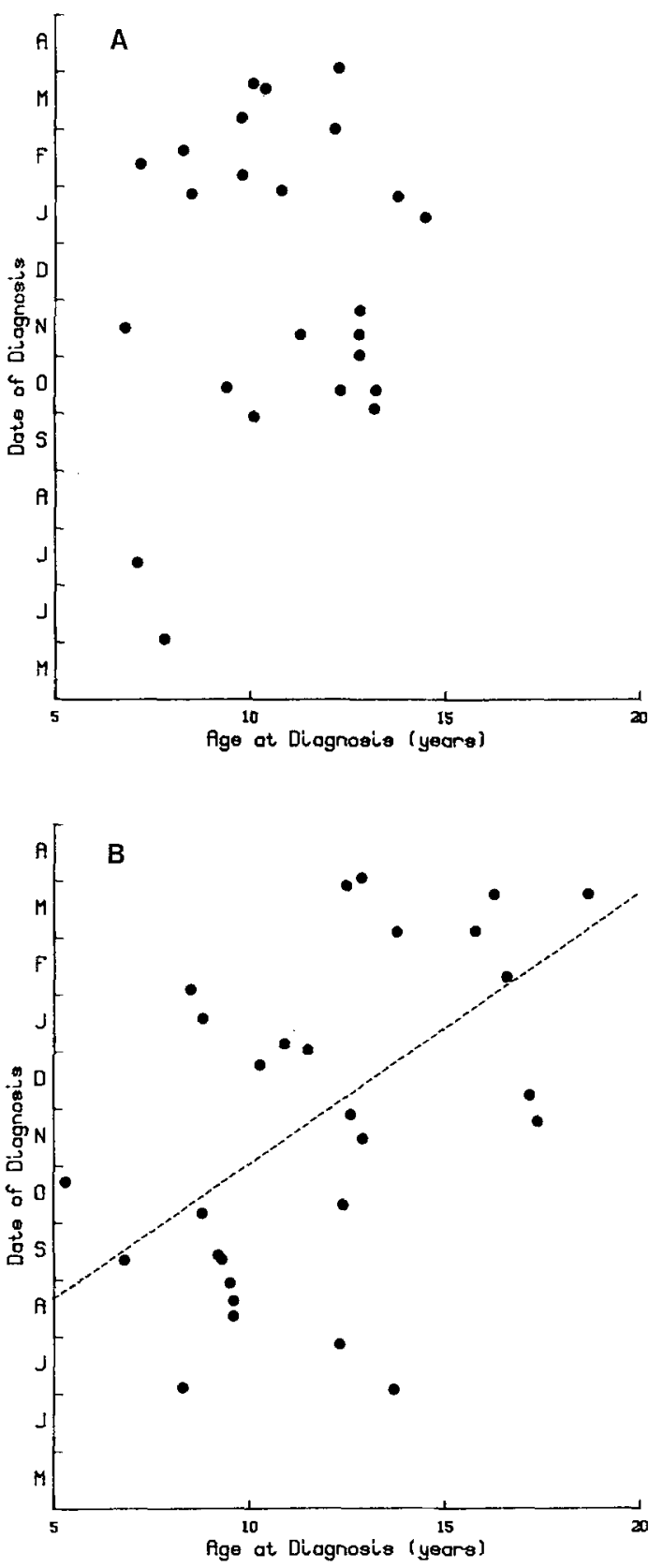

Fig. 4. A Date of diagnosis plotted against age for the 24 DR3-positive cases. B Date of diagnosis plotted against age for the 28 DR3-negative cases

studied a paediatric sample of Type 1 diabetic patients and noted that B8/B15 combination cases seemed prone to onset in winter, rather than autumn. The report did not compare seasonality of onset for HLA-B8- or DR3-positive versus negative patients. In the report of the Eighth International Histocompatibility Workshop [23], HLA-DR4-positive patients were described as significantly more likely to have had their onset during the last 3 months of the year. This finding was described as tentative, since many other combinations of months can be considered (and this multiplicity was not adjusted for) and since data from different centres had been pooled for the analysis. Our sample did not provide strong support for this hypothesis; however, we do not feel that our data allow precise determinations of time of onset of diabetes.

We compared DR3-positive and DR3-negative diabetic patients, rather than $\mathrm{B} 8$-positive and $\mathrm{B} 8$-negative, since evidence suggests that $B 8$ is a risk factor only because it is in linkage disequilibrium with DR3 [9]. Our data showed significant evidence of seasonality in diabetic cases who were DR3-positive and no significant evidence of seasonality in DR3-negative cases, confirming the earlier finding of Rolles et al. [21].

While the patterns of times of diagnosis were somewhat different for DR3-positive versus DR3-negative cases (Fig.2), it would be simplistic to summarize the differences by a claim that seasonality is characteristic of DR3-positive but not of DR3-negative cases. Perhaps the most striking difference suggested by our data is that the bimodality evident in the DR3-positive group (Fig. 2A) seems to be absent in the DR3-negative group (Fig. 2B). In the DR3-positive sample, the 2-month period centred in late December showed as low a density of new cases as was seen in May; no such winter nadir appeared in the DR3-negative data. The summer time patterns were more similar. In both groups, the drop-off in new diagnoses was steepest in April. By August, the incidence of new cases had returned to winter rates in the DR3-negative group, while the DR3-positive group showed a slightly later increase.

The differences seen in the seasonal patterns of diagnosis for DR3-positive versus DR3-negative cases of Type 1 diabetes suggest a genetic influence on time of year of diagnosis. DR3-positive cases may form a relatively homogeneous group, representing a subcategory of Type 1 diabetic patients that is aetiologically more homogeneous than the DR3-negative type. Perhaps the two modes of the distribution for DR3-positive cases reflect two pathogenic processes, while the disease in the more heterogeneous DR3-negative cases is either due to more than two causal pathways, or to the same aetiological factors but with a more variable latency of effect.

The relationship that we have observed in the DR3-negative group between age and time of year at diagnosis is intriguing, but must be confirmed. If real, such a pattern could reflect an association with an infectious disease that appears in late summer in the younger population, and then moves over to the high schools and the adult population later in the year. Alternatively, an initiating aetiological event could occur fairly simultaneously throughout the population, but have a latency of effect that is strongly dependent on age in DR3-negative pre-diabetic subjects.

Acknowledgements. The authors are grateful to B. Alden for typing the manuscript. This investigation was supported in part by NIH grants AM17047, AM30780, AM00535, HL17265 and CA18029, and a grant from the Juvenile Diabetes Foundation. 


\section{References}

1. Adams SF (1926) The seasonal variation in the onset of acute diabetes: the age and sex factor in 1000 diabetic patients. Arch Intern Med 37: 861-864

2. Christau B, Kromann H, Anderson OO, Christy M, Buschard K, Arnung K, Kristensen IH, Peitersen B, Steinrud J, Nerup J (1977) Incidence, seasonal and geographical patterns of juvenile-onset insulin-dependent diabetes mellitus in Denmark. Diabetologia 13: 281-284

3. Craighead JE (1978) Current views on the etiology of insulin-dependent diabetes mellitus. N Engl J Med 299: 1439-1445

4. Gamble DR, Taylor KW (1969) Seasonal incidence of diabetes mellitus. Br Med J 3: 631-633

5. Gamble DR (1976) A possible virus etiology for juvenile diabetes. In: Creutzfeldt W, Kobberling J, Neel JV (eds) The genetics of diabetes mellitus. Springer-Verlag, New York, pp 95-105

6. Gleason RE, Kahn CB, Funk IB, Craighead JE (1982) Seasonal incidence of insulin-dependent diabetes in Massachusetts, 1964-1973. Int J Epidemol 11: 39-45

7. Durruty P, Ruiz F, Garcia de los Rios M (1979) Age at diagnosis and seasonal variation in the onset of insulin-dependent diabetes in Chile (southern hemisphere). Diabetologia 17: 357-360

8. MacMillan DR, Kotoyan M, Zeidner D (1977) Seasonal variation in the onset of diabetes in children. Pediatrics 59:113-115

9. Farid NR, Sampson L, Noel P, Barnard J, Davis AJ, Hillman DA (1979) HLA-D-related (DRw) antigens in juvenile diabetes mellitus. Diabetes 28: $552-557$

10. Illeni MT, Pellegris G, Del Guercio MJ, Tarantino A, Busetto F, Di Pietro C, Clerici E, Garotta G, Chiumello G (1977) HLA antigens in diabetic children. Diabetes 26:870-873

11. Rotter JI, Rimoin DL (1978) Heterogeneity in diabetes mellitusupdate 1978. Diabetes 27:599-605

12. Rotter JI, Rimoin DL (1981) The genetics of the glucose intolerance disorders. Am J Med 70: 116-126

13. Palmer JP, Cooney MK, Ward RH, Hansen JA, Brodsky JB, Ray CG, Crossley JR, Asplin CM, Williams RH (1982) Reduced Coxsackie antibody titres in Type 1 (insulin-dependent) diabetic patients presenting during an outbreak of Coxsackie B3 and B4 infection. Diabetologia 22: $426-429$

14. NIAID Manual of Tissue Typing Techniques, 1979-1980. NIH Publication No. 80-545: 39
15. Terasaki PI (1980) HLA-DR joint report. In: Terasaki PI (ed) Histocompatibility testing, 1980. UCLA Tissue Typing Laboratory, Los Angeles, California, pp 506-591

16. Mickelson EM, Nisperos B, Thomas ED, Hansen JA (1982) Definition of LD " $4 \times 7$ ", a unique HLA-D specificity defined by two homozygous typing cells. Human Immunol 4: 79-86

17. Mardia KV (1972) Statistics of directional data. Academic Press, London, pp 182-186

18. Hajek J (1969) Non-parametric methods. Holden-Day, San Francisco, pp 8-9, 45

19. Gould AL (1969) A regression technique for angular variates. Biometrics 25: 683-700

20. Cudworth AG, Gamble DR, White GBB, Lendrum R, Woodrow JC, Bloom A (1977) Aetiology of juvenile-onset diabetes. Lancet $1: 385-388$

21. Rolles CJ, Rayner PHW, Mackintosh P (1975) Aetiology of juvenile diabetes. Lancet 2: 230

22. Barbosa J, Noreen H, Goetz F, Simmons R, Najarian J, Yunis EJ (1976) Juvenile diabetes and viruses. Lancet 1: 371

23. Svejgaard A, Platz P, Ryder LP (1980) Insulin-dependent diabetes mellitus. In: Terasaki PI (ed) Histocompatibility Testing, 1980. UCLA Tissue Typing Laboratory, Los Angeles, California, pp 638-639

24. Craighead JE, McLane MF (1968) Diabetes mellitus: induction in mice by encephalomyocarditis virus. Science 162: 913-914

25. Gamble DR, Kinsley NL, Fitzgerald MG, Bolton R, Taylor KW (1969) Viral antibodies in diabetes mellitus. Br Med J 3:627-630

26. Yoon J-W, Austin M, Onodera T, Notkins AL (1979) Virus induced diabetes mellitus: isolation of a virus from the pancreas of a child with diabetic ketoacidosis. N Eng J Med 300: 1173-1179

27. Craighead JE (1981) Viral diabetes mellitus in man and experimental animals. Am J Med 70: 127-134

Received: 20 December 1982

and in revised form: 9 November 1983

Dr. C. Weinberg

Biometry and Risk Assessment Program

N.I.E.H.S.

P.O. Box 12233

Research Triangle Park, NC 27709, USA 